\title{
Creation of journal-based publication profiles of scientific institutions - A methodology for the interdisciplinary comparison of scientific research based on the J-factor
}

\author{
RAFAEl BALl, BERnHARD MitTermaier, DiRK TUNGER \\ Forschungszentrum Jülich, 52425 Jülich, Germany
}

\begin{abstract}
A form of normalisation is presented for the evaluation of citation data on multidisciplinary research. This method is based on the existing classification according to the publishing journals and not on the classification of output according to ISI subject categories. A publication profile is created for each institution to be investigated. This profile accounts for the weight of publications in a journal, represented by the number of publications as a proportion of the total output of the institution. In accordance with this weight, the citation rate of each journal is compared to a qualified relative indicator. The final result is a relative citation rate $\mathrm{J}$, which is the relative perception of the performance of an institution accounting for its publication and citation habits and makes a transdisciplinary comparison possible.
\end{abstract}

\section{Introduction}

The widespread use of the performance-oriented allocation of funds and excellence initiatives in science and research has led to questions concerning fair national and international bibliometric benchmarks for comparing scientific institutions becoming a hot topic.

"Every enterprise and almost every organisation or corporation is confronted with the task to monitor and evaluate the performance [...] of its teams, or of the whole unit" [WAGNER-DÖBLER, 2003, P. 145].

The focus is on research institutions as creators of a steadily growing, multidisciplinary scientific output [PRICE, 1963]. These compete with each other to rank among the leading institutions in their disciplines internationally and also to document their position through the perception of their publications. Since the range of publications is continuously increasing worldwide, a global competition has come into being [see MERVIS, 2007, P. 582; BROAD, 2004, P. 1] with the scientific institutions as its main actors. The aim is to achieve a high international visibility for institutions and countries. "The increasing significance of science and research, and the key role played by research institutions in the global competition for innovation are giving rise to an

Received September 19, 2008; Published online March 18, 2009

Address for correspondence:

RAFAEL BALL

E-mail: r.ball@fz-juelich.de 
increasing need for both comprehensive and differentiated information. [...] This information need cannot be met with simple one-dimensional rankings nor can it be met with selected opinions or impressions alone" [translation of DA POZZO \& AL., 2001, P. 15]. It should also be noted that no individual indicator is capable of providing a compact ultimate answer to the question of the quality of scientific research.

\section{Aspects and methods of bibliometric evaluations}

When using bibliometrics to evaluate scientific work, the central questions posed are always similar:

- In what journals does an institution predominantly publish?

- What thematic focus is pursued by an institution?

- What journals promise above-average citation success?

- What perception does a certain institution receive compared to a selected benchmark on a national or international level?

- How can different institutions working in the same field of research be compared with each other?

- How can institutions working in different fields of research be compared with each other?

- What information can be gained by a changed or unchanged positioning of an institution in a ranking in the form of regular monitoring?

See: [DA POZZO \& AL., 2001, P. 18]

In answering these questions, a careful approach is required, particularly for multidisciplinary institutions (research campuses and universities) as it is not easy to evaluate how the institution as a whole is positioned in comparison with a benchmark [ADAM, 2002]. When comparing on an interdisciplinary basis a normalisation must be carried out in any case: "Citation (and publication) practices vary between fields and over time" [GARFIELD, 1989, P. 96] because disciplines fall back on different methods to identify problems and to tackle them. Here, different communication methods also come into play. Mathematics, for example, is considered to be a field with a lower number of references and thus a less intensive citation "traffic" than biology or medicine [ZITT \& AL., 2005, P. 374; ADAM, 2002, P. 727]. “As citation practices strongly depend on fields, field normalisation is recognised as necessary for fair comparison of figures in bibliometrics and evaluation studies" [ZITT \& AL., 2005, P. 373].

Van Raan describes the creation of research profiles [VAN RAAN, 2004, P. 34]: “A further important step is the breakdown of the institute's output into research fields. This provides a clear impression of the research scope or 'profile' of the institute" [VAN RAAN, 2004, PP. 33F]. The literature describing this type of output profile is already quite extensive, comparing for example individual countries, disciplines or institutions 
and mapping their focused research activities and the resulting changes [See: GARG \& AL., 2006, PP. 151-166; MITTERMAIER \& AL., 2007; TIJSSEN \& AL., 2002, etc.].

In order to achieve a pure output profile for a field-normalised perception analysis, van Raan investigates "the field-normalised impact values of the institute's research in [...] different fields [...]" [VAN RAAN, 2004, P. 33]. He uses this method to gain a comprehensive insight into scientific research in Germany [see TIJSSEN \& AL. 2002, etc.]. Van Raan termed the requisite indicator that estimates the field-normalised perception the field citation score (FCS) or FCSm "in the case in which more fields are involved" [VAN RAAN, 2004, P. 30].

It should be noted that field normalisation is based on the classification of journals as one of the 230 total ISI subject categories. Each journal is assigned to at least one of the categories and multiple classifications are often found. A journal can therefore be assigned to up to five different fields. This means that a single article can be taken into account more or less often depending on the number of subject categories in the journals in which it has been published. Objectively, this is in no way justified and it leads to avoidable distortions. Further distortions are caused by non-uniform distribution of multiple classifications and the different size of the individual disciplines. "As a result, field-normalised indicators are not only, trivially, dependent on the delineation of fields, but also, for a given multi-level classification, dependent on the hierarchical level of observation in a particular classification. An article may exhibit very different citation scores, or rankings when compared within a narrow speciality or a large academic discipline" [ZITT \& AL., 2005, P. 391].

\section{The J Factor}

In the following, a method is presented that works separately from the disciplines, in other words field-normalised, and simultaneously takes each article into account once only. It is based on the fact that every scientific institution has an individual publication profile characterised by the specific distribution of publications among the total number of journals. The perception of the performance of each institution (citation rate of articles) is compared for each journal with the standard. Each journal as a proportion of the total output is taken into account when calculating the total value for perception. This value is what we call the $\mathrm{J}$ factor. This means that for publications in all of the journals, in which the institution under analysis publishes, a perception ratio is ascertained in comparison with the identical journal of the standard and calculated with a weighting factor.

$$
J(I, R)=\sum_{S} \frac{\mathrm{cpp}_{\mathrm{I}}(\mathrm{S})}{\mathrm{cpp}_{\mathrm{R}}(\mathrm{S})} \bullet \frac{\mathrm{p}_{\mathrm{I}}(\mathrm{S})}{\mathrm{p}_{\mathrm{I}, \mathrm{ges}}}
$$

where

$\mathrm{J}(\mathrm{I}, \mathrm{R})$ : $\mathrm{J}$ factor of institution $\mathrm{I}$, in relation to the standard (relative indicator) $\mathrm{R}$ 
S: $\quad$ serial

$\operatorname{cpp}_{\mathrm{I}}(\mathrm{S})$ : average citation rate of publications by institution I in journal $\mathrm{S}$

$\operatorname{cpp}_{R}(\mathrm{~S})$ : average citation rate of publications by standard $\mathrm{R}$ in journal $\mathrm{S}$

$\mathrm{p}_{\mathrm{I}}(\mathrm{S})$ : number of publications by institution $\mathrm{I}$ in journal $\mathrm{S}$

$\mathrm{p}_{\mathrm{I}, \mathrm{ges}}$ : total number of publications by institution I

As a result of the relationship $\mathrm{cpp}=\mathrm{c} / \mathrm{p}$, we can rewrite the formula as

$$
J(I, R)=\frac{1}{p_{I, g e s}} \sum_{S} \frac{c_{I}(S)}{\operatorname{cpp}_{R}(S)},
$$

where

$\mathrm{c}_{\mathrm{I}}(\mathrm{S})$ : number of publications by institution $\mathrm{I}$ in journal $\mathrm{S}$.

The Relative Indicator $\mathrm{R}$ as a benchmark can be defined on a national scale (institution as against the nation-state to which it belongs), on a multistate scale (e.g. EU-27, ASEAN) or on an international scale. For a comparison of a group of institutions with each other (e.g. Ivy League universities), the total number of publications by the group can be used for benchmarking.

Only those publications by institution I in journals $\mathrm{S}$ can be taken into account, for which the corresponding information is also available for the relative indicator $\mathrm{R}$ (number of publications and citations). This is the case for example in the cover-tocover indexed databases such as Science Citation Index, Social Sciences Citation Index and Arts \& Humanities Citation Index (Thomson Scientific). The analyses outlined in Chapter 4 were conducted with the aid of these databases.

The $\mathrm{J}$ factor therefore describes the relative perception $\mathrm{J}$ of an institution $\mathrm{I}$ in comparison with a defined relative indicator R. Through summation over the perception quotients for each individual journal, weighted with the number of publications in each of the journals as a proportion of all publications.

A result that can be compared to that generated by the $\mathrm{J}$ factor is generated by the JCSm indicator (mean Journal Citation Score), which is described in the literature [see VAN RAAN, 2004, P. 29]. The quotient CPP/JCSm must first be determined and related to the weight of publications in a set:

$$
\frac{\mathrm{CPP}}{\mathrm{JCSm}}(\mathrm{I})=\frac{\sum \mathrm{C}_{1}}{\sum_{\mathrm{S}} \sum_{\mathrm{D}} \mathrm{P}_{\mathrm{S} ; \mathrm{D} ; 1} \bullet \mathrm{C}_{\mathrm{S} ; \mathrm{D} ; \mathrm{ges}}}
$$

where:

$\begin{array}{ll}\frac{\mathrm{CPP}}{\mathrm{JCSm}}(\mathrm{I}) & \mathrm{CPP} / \mathrm{JCSm} \text { of institution I } \\ \mathrm{C}_{\mathrm{I}}: & \text { total number of citations for all publications by institution I } \\ \mathrm{P}_{\mathrm{I}}: & \text { total number of publications by institution I } \\ \mathrm{S}: & \text { serial }\end{array}$




\section{D: document type \\ $\mathrm{P}_{\mathrm{S} ; \mathrm{D} ; \mathrm{I}}: \quad$ number of publications by institution I with document type $\mathrm{D}$ in serial $\mathrm{S}$ \\ $\mathrm{C}_{\mathrm{S} ; \mathrm{D} ; \mathrm{ges}}$ : number of citations of all publications with document type $\mathrm{D}$ in serial $\mathrm{S}$}

The following concrete differences can be determined between the $\mathrm{J}$ factor and the CPP/JCSm: for the $\mathrm{J}$ factor, only WoS articles are used; ${ }^{1}$ there is no other differentiation according to the type of document or the year of publication. This means that all documents of an observation period available in WoS which correspond to the search criteria for an institution or are to be included in the standard are considered in the calculation.

In addition, self-citations will not be excluded, because it has not been definitely clarified yet how to determine these in the literature. The tendency here is not to exclude self-citations as long as misuse is not suspected [see also GLÄNZEL, 2008].

In other places in the literature, a similar indicator is also discussed, namely the journal-based relative citation rate [RCR; see SCHUBERT \& BRAUN, 1993]: "In general, sets of papers under investigation are published in various journals. In that case, the mean expected citation rate $\left(\mathrm{MECR}^{2}\right)$ can be defined as the weighted average citation rate of the journals, the papers in question were published in. (The weights are, of course, the publication frequencies in the respective journals.) The mean observed citation rate $\left(\mathrm{MOCR}^{3}\right)$, i.e. the average citation rate per paper can again be related to the MECR to result in the relative citation rate $\left(\mathrm{RCR}^{4}\right)$, indicating the relative impact of the papers in question among the average papers of the publishing journals as reference standard" [SCHUBERT \& BRAUN, 1993, P. 23].

This publication does not primarily aim to introduce a new indicator to the community [see also: SCHUBERT \& BRAUN, 1986, PP. 281-291], but to highlight the need of multidisciplinary research institutions through the $\mathrm{J}$ factor to intensify and further disseminate journal-based and thus distortion-free ranking as a standard of science evaluation. This publication is to refresh a topic in the community which will be of importance as a basis for transparent standards from the perspective of a multidisciplinary research institution. The method outlined can be differentiated from other relative journal citation rates [see, for example, VINKLER, 1996, PP. 223-236] which use, for example, the impact factor of a journal instead of its citation rate. When the IF is included in a relative indicator, the composition of the standard publication portfolio may not exactly correspond to the composition of the investigated institute.

\footnotetext{
${ }^{1}$ No documents of other bibliographic or citation databases are included

${ }^{2}$ MECR equals JCSm

${ }^{3}$ MOCR equals CPP

${ }^{4}$ RCR equals CPP/JCSm
} 
Thus, differences may occur in the observation period or in the selection of document types included. This inaccuracy is prevented by the $\mathrm{J}$ factor, which ensures that work is performed on both sides for an identical period and identical document types using the citation rate.

\section{Examples and applications}

The $\mathrm{J}$ factor will be applied to three fictive institutions by way of example in order to explain the method more precisely. Profiles will therefore be created for the three different fictive institutions and their publication and citation data will be compared with the corresponding standard.

Each of the three profiles represents one institution whose expected impact compared to the relative indicator is:

- identical,

- half as high,

- twice as high.

The composition of the standard is defined individually according to the journals selected by the institution. The proportion of publications in a journal is calculated in relation to the institution's total output with the citation rate of the institution being related to this journal in relation to the relative indicator. This consists of all journals in which the institution being analysed has published. This is used to compare the impact of publications by an institution in a journal (according to the weight of the journal in terms of the total output of an institution) with the impact of all publications in this journal, which belong to the benchmark (e.g. country, world, etc.). The comparison is conducted journal-by-journal and produces a cumulative value as the final result of perception of the research performance as a percentage (relative citation rate).

For the sake of overview, the number of journals used is deliberately kept to a minimum for the fictive institutions.

Table 1. Example of an institution with a $\mathrm{J}$ factor of $100 \%$ (sum of incremental citation rates)

\begin{tabular}{|l|r|r|r|}
\hline & \multicolumn{3}{|c|}{ Standard R1 } \\
\hline & P & C & CPP \\
& & & \\
\hline Journal A & 10 & 100 & 10 \\
\hline Journal B & 5 & 20 & 4 \\
\hline Journal C & 20 & 400 & 20 \\
\hline
\end{tabular}

\begin{tabular}{|r|r|r|r|r|c|}
\hline \multicolumn{7}{|l|}{ P } & C & CPP & $\begin{array}{c}\text { Relative } \\
\text { Institution I1 } \\
\text { (CPP rel) }\end{array}$ & $\begin{array}{c}\text { Weight } \\
\text { of the } \\
\text { journals }\end{array}$ & $\begin{array}{c}\text { Incremental } \\
\text { relative citation } \\
\text { rate }\end{array}$ \\
\hline 1 & 10 & 10 & $100 \%$ & $33 \%$ & $33.3 \%$ \\
\hline 1 & 4 & 4 & $100 \%$ & $33 \%$ & $33.3 \%$ \\
\hline 1 & 20 & 20 & $100 \%$ & $33 \%$ & $33.3 \%$ \\
\hline
\end{tabular}


Table 2. Example of an institution with a $\mathrm{J}$ factor of $50 \%$

\begin{tabular}{|l|r|r|r|}
\hline & \multicolumn{3}{|c|}{ Standard R2 } \\
\hline & P & C & CPP \\
& & & \\
\hline Journal A & 10 & 100 & 10 \\
\hline Journal B & 5 & 20 & 4 \\
\hline Journal C & 20 & 400 & 20 \\
\hline
\end{tabular}

\begin{tabular}{|r|r|r|c|c|c|}
\hline \multicolumn{7}{|l|}{ P } & C & CPP & $\begin{array}{c}\text { Relative } \\
\text { citation rate } \\
(\text { CPP rel })\end{array}$ & $\begin{array}{c}\text { Weight } \\
\text { of the } \\
\text { journals }\end{array}$ & $\begin{array}{c}\text { Incremental } \\
\text { relative citation } \\
\text { rate }\end{array}$ \\
\hline 2 & 10 & 5 & $50 \%$ & $40 \%$ & $20.0 \%$ \\
\hline 1 & 4 & 4 & $100 \%$ & $20 \%$ & $20.0 \%$ \\
\hline 2 & 10 & 5 & $25 \%$ & $40 \%$ & $10.0 \%$ \\
\hline
\end{tabular}

Table 3. Example of an institution with a J factor of $200 \%$

\begin{tabular}{|l|r|r|r|}
\hline & \multicolumn{3}{|c|}{ Standard R3 } \\
\hline & P & C & CPP \\
& & & \\
\hline Journal C & 20 & 400 & 20 \\
\hline Journal D & 10 & 40 & 4 \\
\hline Journal E & 25 & 250 & 10 \\
\hline
\end{tabular}

\begin{tabular}{|r|r|r|r|r|r|}
\hline \multicolumn{7}{|l|}{ P } & C & CPP & $\begin{array}{c}\text { Relative } \\
\text { citation rate } \\
(\mathrm{CPP} \text { rel })\end{array}$ & $\begin{array}{c}\text { Weight } \\
\text { of the } \\
\text { journals }\end{array}$ & $\begin{array}{c}\text { Incremental } \\
\text { relative } \\
\text { citation rate }\end{array}$ \\
\hline 3 & 180 & 60 & $300 \%$ & $50 \%$ & $150.0 \%$ \\
\hline 2 & 4 & 2 & $50 \%$ & $33 \%$ & $16.7 \%$ \\
\hline 1 & 20 & 20 & $200 \%$ & $17 \%$ & $33.3 \%$ \\
\hline
\end{tabular}

Every institution is assessed according to their individual publication output. This means that the calculated standard is customised for each institution. This does not mean that it is chosen at random. It directly reflects the publication habits of an institution.

With the data generated, it is possible to come to a conclusion with regard to which institution has the highest perception in relation to their research environment. The journals in which the institution under analysis surpasses the relative indicator can be identified, as can the journals in which the institution has not. "If we find a smaller field with a relatively low impact (i.e. a field in the lower part, the 'tail' of the profile), this does not necessarily mean that the (few) publications of the institute in this particular field are 'bad'. Often these small fields in a profile are those that are quite 'remote' from the institute's core fields" [VAN RAAN, 2004, P. 33]. What van Raan implements here as subject categories also holds for journal-based profiles. A small number of publications in a journal and a simultaneously low impact indicate a journal in which scientists from other disciplines predominantly publish.

The method outlined can be compared to the field normalisation method used by VAN RAAN [2004]. In order to determine the J factor, however, the classification according to ISI subject categories is replaced by the basic classification in the journals.

A clear advantage of normalisation using the $\mathrm{J}$ factor on a journal basis compared to a field normalisation based on subject categories is that the heavily discussed assignment of journals to categories does not come into play: "Taking into consideration that journals are often not devoted to a single topic, the delimitation of subject areas based on journal assignment is neccessarily less precise [...]" [GLÄNZEL, 1999, P. 428]. Although the composition of categories is documented in the Journal Citation Report, the different sizes of the individual categories can lead to distortions 
depending on the aggregation level of the underlying classification (see [ZITT, 2005, P. 391]).

The origin of this type of distortion is demonstrated in the following using the three institutions as an example. Journals A-E are assigned to four subject categories (Table 4).

Based on the assignment of the journals to the subject categories in Table 4, the perception of institutions I1-I3 is compared to a relative indicator with this changed configuration.

Table 4. Assignment of the fictive subject categories to the journals listed above

\begin{tabular}{llll}
\hline Subject category 1 & Subject category 2 & Subject category 3 & Subject category 4 \\
\hline Journal A & Journal A & Journal A & Journal C \\
Journal D & Journal B & Journal B & Journal D \\
& Journal D & & \\
& Journal E & & \\
\hline
\end{tabular}

Table 5. Institution I1 achieves a total perception of $104.2 \%$ with a field normalisation according to subject categories (with the journal method: $100 \%$ )

\begin{tabular}{|l|r|r|r|}
\hline & \multicolumn{3}{|c|}{ Standard R1 } \\
\hline & & & \\
& & & \\
\hline SC 1 & 20 & 140 & 7.0 \\
\hline SC 2 & 50 & 410 & 8.2 \\
\hline SC 3 & 15 & 120 & 8.0 \\
\hline SC 4 & 30 & 440 & 14.7 \\
\hline
\end{tabular}

\begin{tabular}{|r|r|r|r|r|r|}
\hline \multicolumn{7}{|l|}{ P } & C & CPP & $\begin{array}{c}\text { Relative } \\
\text { citation rate } \\
(\mathrm{CPP} \text { rel })\end{array}$ & $\begin{array}{c}\text { Weight } \\
\text { of the } \\
\text { journals }\end{array}$ & $\begin{array}{c}\text { Incremental } \\
\text { relative } \\
\text { citation rate }\end{array}$ \\
\hline 1 & 10 & 10.0 & $143 \%$ & $17 \%$ & $23.8 \%$ \\
\hline 2 & 14 & 7.0 & $85 \%$ & $33 \%$ & $28.5 \%$ \\
\hline 2 & 14 & 7.0 & $88 \%$ & $33 \%$ & $29.2 \%$ \\
\hline 1 & 20 & 20.0 & $136 \%$ & $17 \%$ & $22.7 \%$ \\
\hline
\end{tabular}

Table 6. Institution 12 achieves a total perception of 55.7\% with a field normalisation according to subject categories (with the journal method: $50 \%$ )

\begin{tabular}{|c|c|c|c|}
\hline & \multicolumn{3}{|c|}{ Standard R2 } \\
\hline & $\mathrm{P}$ & $\mathrm{C}$ & CPP \\
\hline SC 1 & 20 & 140 & 7.0 \\
\hline SC 2 & 50 & 410 & 8.2 \\
\hline SC 3 & 15 & 120 & 8.0 \\
\hline SC 4 & 30 & 440 & 14.7 \\
\hline
\end{tabular}

\begin{tabular}{|r|r|r|c|c|c|}
\hline \multicolumn{7}{|l|}{ P } & C & CPP & $\begin{array}{c}\text { Relative } \\
\text { citation rate } \\
\text { (CPP rel) }\end{array}$ & $\begin{array}{c}\text { Weight } \\
\text { of the } \\
\text { journals }\end{array}$ & $\begin{array}{c}\text { Incremental } \\
\text { relative citation } \\
\text { rate }\end{array}$ \\
\hline 2 & 10 & 5.0 & $71 \%$ & $20 \%$ & $14.3 \%$ \\
\hline 3 & 14 & 4.7 & $57 \%$ & $30 \%$ & $17.1 \%$ \\
\hline 3 & 14 & 4.7 & $58 \%$ & $30 \%$ & $17.5 \%$ \\
\hline 2 & 10 & 5.0 & $34 \%$ & $20 \%$ & $6.8 \%$ \\
\hline
\end{tabular}

The results varied for the perception of institutions I1-I3 calculated according to subject categories, based on identical journal publications of the three fictive institutions and the results from Tables $1-3$. This deviation can be either very small amounting to a few percent or it can amount to $20 \%$ or more. Rankings that were created for an institution with an identical set of reference data can deviate strongly from each other. 
Table 7. Institution I3 achieves a total perception of $160.4 \%$ with a field normalisation according to subject categories (with the journal method: $200 \%$ )

\begin{tabular}{|l|r|r|r|}
\hline & \multicolumn{3}{|l|}{ Standard R3 } \\
\hline & P & C & CPP \\
& & & \\
\hline SC 1 & 20 & 140 & 7.0 \\
\hline SC 2 & 50 & 410 & 8.2 \\
\hline SC 4 & 30 & 440 & 14.7 \\
\hline
\end{tabular}

\begin{tabular}{|r|r|r|c|c|c|}
\hline \multicolumn{7}{|c|}{ P } & C & CPP & $\begin{array}{c}\text { Relative } \\
\text { citation rate } \\
\text { (CPP rel) }\end{array}$ & $\begin{array}{c}\text { Weight } \\
\text { of the } \\
\text { journals }\end{array}$ & $\begin{array}{c}\text { Incremental } \\
\text { relative citation } \\
\text { rate }\end{array}$ \\
\hline 2 & 4 & 2.0 & $29 \%$ & $20 \%$ & $5.7 \%$ \\
\hline 3 & 24 & 8.0 & $98 \%$ & $30 \%$ & $29.3 \%$ \\
\hline 5 & 184 & 36.8 & $251 \%$ & $50 \%$ & $125.5 \%$ \\
\hline
\end{tabular}

Depending on the subject categories to which the journal is assigned and their configuration, this can be either better or worse for an institution. An institution fares worse in a ranking based on subject categories than in the journal method presented above if it generally publishes in low-impact journals. Even if these articles top the perception of the journal in which they were published, they can still give rise to an under-average rating compared to an entire discipline. Furthermore, the multiple registration of articles can also have a generally cumulative effect, particularly for articles that lie well below or well above the respective average for that discipline, and it also often slips into calculations through the multiple classification of journals.

The model presented will now be explained in more detail using a concrete example. Three German cities (Hamburg, Cologne, and Munich) with a different number of scientific institutions and different thematic priorities are compared (observation period: 2002-2006). For each of the three cities, the national benchmark is chosen and the relative citation rate based on the journals is calculated for each city according to the individual publication profiles. If a ranking is performed for the three cities using the method described, the following result is achieved.

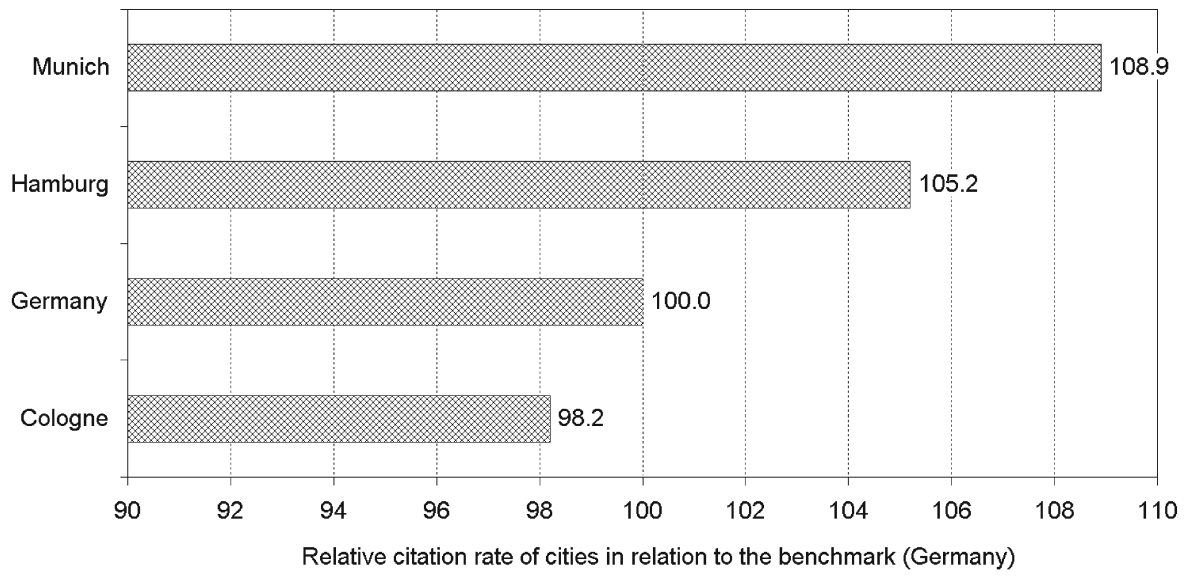

Figure 1. Ranking of the three cities indicating the relative citation rate in relation to a standard 
In order to better visualise the calculation of $\mathrm{J}$ for the example of the three cities, a selection of standard indicators will be compared to the $\mathrm{J}$ factor in the following table. It should be noted that except for the $\mathrm{J}$ factor all other indicators are discipline-related and only deliver approximate values because the special focus on the disciplines of a city was not further considered in this table:

Table 8. Comparison of different indicators (2002-2006)

\begin{tabular}{lrrrrrc}
\hline & \multicolumn{1}{l}{ P } & \multicolumn{1}{l}{ C } & CPP & \multicolumn{1}{c}{ h } & \multicolumn{1}{c}{ J } & \# of different sources \\
\hline Germany (Benchmark) & 453986 & 2484513 & 5,5 & 228 & 100.0 & 10361 \\
Hamburg & 19362 & 121595 & 6,3 & 95 & 105.2 & 3449 \\
Cologne & 12734 & 70554 & 5,5 & 74 & 98.2 & 2628 \\
Munich & 40523 & 263498 & 6,5 & 124 & 108.9 & 4944 \\
\hline
\end{tabular}

It can be clearly seen that Munich achieves a performance of about $9 \%$ above the German average in the journals in which the scientists there publish. Hamburg achieves a result that is $5.2 \%$ above the benchmark and Cologne lies $1.8 \%$ below.

\section{Summary}

The journal-based normalisation method presented here has some advantages over normalisation on a subject-category level:

Each article is counted once only, which means that all types of distortion caused by assigning the same article to several subject categories are therefore avoided.

A field-normalised ranking according to subject categories does not consider whether a publication was positioned in a low- or high-impact journal in the corresponding subject category. Therefore, this ranking does not take into account the fact that the impact factors of journals in the same subject category can differ by two to three orders of magnitude. The subject category "multidisciplinary science", for example, includes the Kuwait Journal of Science \& Engineering as well as Science and Nature. This is not important for the journal-based normalisation presented here. An institution is compared to a constructed specialist community and only the exact composition of this community determines its journal-based publication profile. It may be objected that an institution or an individual scientist could publish consciously in a low-impact journal to reach a higher relative citation rate. This objection can be contradicted as follows: first of all, scientists would not consciously "give away" a valuable article and publish it in a journal which does not match the quality of the article at all. What would be the benefit? If scientists frequently undersell themselves in journals, their relative citation rate would possibly rise. However, this may have negative consequences for personal or institute-related indicators $(\mathrm{C}, \mathrm{CPP}, \mathrm{h})$. For this reason, the $\mathrm{J}$ factor does not replace any other indicators already introduced, but 
complements the available set. Another reason against the conscious publication of articles in low-impact journals is the scientists' associated uncertainty whether the scientific community would accept a low-impact journal article to the same extent. This means that they could not be sure whether they can reach a comparable number of citations with such a strategy because to some extent the success of a publication is also connected with the journal and its reputation. Thus, it can be assumed that scientists would not change their publication behaviour in the case of an increasing usage of journal-based relative indicators.

For the assumed case that an investigated institution is only able to place a large part of its output in mediocre journals of a discipline whereas comparable institutions publish in top-class journals, it must be noted that the $\mathrm{J}$ factor is only one parameter in a large number of indicators. It is conceivable that the part of an institution's publications in the top 10 percent of the journals of a discipline could be recorded or the part of the publications that belong to the top 5 percent of a discipline (based on the number of citations in one publication). As other bibliometric indicators, the $\mathrm{J}$ factor does not use a number to record the complexity of scientific publications and their perception as a whole, but rather considers one aspect.

Further advantages compared to a field normalisation (such as CPP/FCSm) are the exclusion of a questionable content-related assignment of the journals to subject categories and a reduction in the distortion which arises through the difficult comparison of rather theoretically oriented journals with rather application-oriented ones. The presumed distortion of a field normalisation assumes that journals do not only differ in their impact, as implied by many advocates of field normalisation, but also according to content-related criteria, which may for example also be caused by a possible shift in priorities.

For the bibliometric evaluation of institutions, this means that the underlying comparison becomes more transparent and comprehensible when the journal method is applied because the benchmark composition is easier to understand for scientists. For institutions that would like to or need to document their scientific performance using publication and citation data, the method presented here represents another step towards more transparent standards and ranking methods.

The results of bibliometric analyses provide greater transparency and clarity, thus giving researchers the opportunity to accept these results more easily, to identify their strengths and weaknesses of their own publication behaviour, and consequently to change this behaviour accordingly in the future. Such opportunities to change their own communication behaviour must be provided for internationally competitive scientific institutions, because after all they are also partly economically dependent on the worldwide response to their research. 
Not only is the more targeted communication behaviour of scientific institutions of benefit to the institutions themselves, but it also leads to more purposeful communication in science. In this way, bibliometrics does not only contribute to the evaluation of science; it also supports the targeted optimisation of scholarly communication.

The increasing application of the journal-based method will optimise rather than replace the method of field normalisation according to subject categories. Multidisciplinary scientific institutions in particular will profit from the journal-based ranking method.

\section{References}

ADAM, D. (2002), The counting house, Nature, 415 (6873) : 726-729.

BROAD, W. (2004). U.S. is losing its dominance in the Sciences. The New York Times, 1 : (03.05.2004).

Da Pozzo, F., I. Maye, A. Roulin Perriard, M. von Ins (2001), Die Schweiz und die weltweite Champions League der Forschungsinstitutionen 1994-1999 - Ein Beitrag zu einem internationalen Benchmarking: Konzept und erste Ergebnisse. Retrieved 30.08.2007, from http://www.cest.ch/Publikationen/2001/cest_11/CEST_2001_11.pdf.

GARFIELD, E. (1989), Evaluating research : Do bibliometric indicators provide the best measures? Essays of an Information Scientist, $12: 93-100$.

GARG, K. C., S. KUMAR, K. LAL (2006), Scientometric profile of Indian agricultural research as seen through science citation index expanded, Scientometrics, 68 (1) : 151-166.

GLÄNZEL, W. (2008), Seven Myths in Bibliometrics. About facts and fiction in quantitative science studies. Collnet Journal of Scientometrics and Information Management, 2 (1) : 9-17.

Glänzel, W., A. Schubert, H.-J. Czerwon (1999), An item-by-item subject classifivation of papers published in multidisciplinary and general journals using reference analysis, Scientometrics, 44 (3) : 427-439.

MERVIS, J. (2007), U.S. output flattens, and NSF wonders why - Scientific publishing, Science, 317 (5838) : 582.

Mittermaier, B., D. Tunger, U. Burkard, S. Ramowsky, H. LeXIS (2007), Bibliometric Analysis on the Scientific Output of India. Retrieved 04.09.2007, from http://www.bibliometrie.de /Bibliometric_report_dlr_India_E_mit_Deckblatt_1971.pdf.

Price, D. J. D. S., Little Science, Big Science, New York, Columbia University Press, 1963.

SCHUBERT, A., T. BRAUN (1986), Relative indicators and relational charts for comparative assesment of publication output and citation impact, Scientometrics, 9 (5-6) : 281-291.

SCHUBERT, A., T. Braun (1993), Reference-standards for citation based assesments, Scientometrics, 26 (1) : 21-35.

Tussen, R., T. VAn Leeuwen, A. VAn RaAn, Mapping the Scientific Performance of German Medical Research. Stuttgart, Schattauer Verlag, 2002.

VAN RAAN, A., Measuring Science. Handbook of Quantitative Science and Technology Research. H. F. MoED, W. GlÄNZEL, U. ScHMOCH, Dordrecht, Kluwer Academic Publishers : 19-50, 2004.

VINKLER, P. (1996), Model for quantitative selection of relative scientometric impact indicators, Scientometrics, 36 (2) : 223-236.

WAGNER-DÖBLER, R. (2005), The system of research and development indicators: entry-points for information agents, Scientometrics, 62 (1) : 145-153.

ZitT, M., S. RAMANANA-RAHARY, E. BASSECOULARD (2005), Relativity of citation performance and excellence measures: From cross-field to cross-scale effects of field-normalisation, Scientometrics, 63 (2) : 373-401. 